\title{
Lymphedema in the Mastectomy Postoperative Period: An Integrative Literature Review
}

\author{
Ana Fátima Carvalho Fernandes*, Glécya Oliveira Vidal, Camila Brasil Moreira, \\ Tiago Barreto de Castro e Silva, Paula Natasha Rodrigues Valentim, Míria Conceição Lavinas Santos \\ Department of Nursing, Federal University of Ceará, Fortaleza, Brazil \\ Email: *afcana@ufc.br
}

Received August 20, 2013; revised September 1, 2013; accepted September 7, 2013

Copyright (c) 2013 Ana Fátima Carvalho Fernandes et al. This is an open access article distributed under the Creative Commons Attribution License, which permits unrestricted use, distribution, and reproduction in any medium, provided the original work is properly cited.

\begin{abstract}
Aims and Objectives: To analyze the evidence available in the literature on the stages during which upper limb lymphedema after mastectomy occurs. Background: Among the adverse effects of breast cancer treatment, lymphedema is the most prevalent. Design: Integrative literature review. Methods: The Latin American and Caribbean Literature on Health Sciences (Literatura Latino-Americana e do Caribe em Ciências da Saúde-LILACS), PubMed, and Cumulative Index to Nursing and Allied Health Literature (CINAHL) databases were used to select the pertinent studies. The identification data for these studies were summarized, and their methodological features and results were extracted. Results: Regarding the time elapsed since surgery, the highest prevalence of lymphedema corresponded to the late postoperative period, and regarding its severity, mild lymphedema was the most prevalent form. The prevalence was also the highest among the women who were subjected to radical mastectomy and radiotherapy. Conclusions: Many women who are undergoing treatment for breast cancer use strategies for the prevention and control of lymphedema of the upper limb following mastectomy. Relevance to Clinical Practice: The findings of the present study might inform future studies aiming to assess strategies that can be started in the immediate and late postoperative stages to detect lymphedema early and prevent the increase of its prevalence during the late postoperative period after mastectomy.
\end{abstract}

Keywords: Breast Cancer; Post-Operative Care; Nursing

\section{Introduction}

Breast cancer is an important global public health problem due to its high incidence and mortality. According to estimates by the World Health Organization (WHO) [1], 1,050,000 new cases are recorded every year worldwide.

The initial treatment is divided into primary, which is surgical and may be complemented with neoadjuvant chemotherapy, and adjuvant, which includes radiation and hormone therapy [2]. There are two main types of surgical approaches: partial and total mastectomy, both of which include simultaneous axillary lymph node dissection. Novel surgical techniques are currently employed, such as sentinel lymph node biopsy (SNB), which predicts the status of the lymph node chain in 95\% of cases, thus allowing for the selective indication of lymph node dissection with the consequent reduction of its side effects [2].

Among the various surgical procedures, mastectomy is

"Corresponding author. associated with the largest number of social, emotional, and physical complications. The latter include involvement of the ipsilateral upper limb, which results in weakness, stiffness, pain, restricted mobility, and lymphedema [3].

Lymphedema of the upper limb is the most prevalent cause of morbidity during the postoperative period after mastectomy [4], consequent to axillary lymph node dissection. The condition, which is associated with the limbs, is characterized by abnormal accumulation of proteins and fluids in the interstitial space, edema, and chronic inflammation $[5,6]$. The risk of lymphedema is associated with axillary dissection and radiotherapy, obesity, extent of the surgical technique, infection, patient age, number of dissected lymph nodes, number of positive lymph nodes, and level of lymph node dissection [4,7].

Estimates of the incidence and prevalence of lymphedema exhibit wide variation in the literature due to the lack of standardization of the diagnostic criteria and 
measurement procedures, the methodological limitations imposed by the studies, variations in the investigated populations, and the length of postoperative follow-up [4].

The main objective and diagnostic techniques for assessing lymphedema are measurement of the upper limb circumference at several sites and volumetric measurement, which is calculated from the displacement of water, based on Archimedes’ principle [8].

Regarding the severity of post-mastectomy lymphe dema, the literature describes the degree of impairment of the affected limb as mild, moderate, and severe [9], or as grades I, II, and III, which are equivalent.

When left untreated, lymphedema progressively increases in the size and degree of severity. As a chronic condition, its treatment is life-long, and thus, the patients require appropriate social support [8].

Because of the above-described considerations, nursing care strategies are crucial during the perioperative period after mastectomy. The participation of nurses as members of a multidisciplinary staff is not restricted to therapeutic procedures but, rather, mainly involves the prevention of lymphedema. Systematization of nursing care helps prevent the progression of complications in the corresponding upper limb, particularly progressive increase of the degree of lymphedema.

The aim of the present study was to analyze the evidence available in the literature regarding the postoperative stages after mastectomy during which lymphedema of the upper limb occurs.

\section{Materials and Methods}

To accomplish the aim of the present study, an integrative literature review was selected, which is a technique that compiles and synthesizes the available scientific information by analyzing the results reported by studies [10].

In integrative literature reviews, the conclusions of studies are summarized to formulate inferences about a specific topic. This type of review can afford a sound basis for the implementation of modifications that improve the quality of nursing assistance by means of research models [11].

As with conventional research, integrative literature reviews also include six stages, namely problem identification, a literature search, categorization of the studies, evaluation of the studies, interpretation of results, and presentation of the integrative review [12].

Based on the identified problem, the following guiding question was formulated: "What is the available scientific information on the postoperative stages after mastectomy during which lymphedema occurs?”

To locate the relevant studies, a wide search was conducted using three databases that were selected as sources for data collection: the Latin American and Car- ibbean Literature on Health Sciences (Literatura Latino-Americana e do Caribe em Ciências da Saúde), PubMed, and the Cumulative Index to Nursing and Allied Health Literature (CINAHL).

The inclusion criteria were as follows: original articles addressing lymphedema of the upper limb during the postoperative period after mastectomy; and articles specifying the degree of severity of lymphedema, which were published from 1996 to 2011 in English, Portuguese, or Spanish. Review studies, editor letters, guidelines and studies which not have relation with our guiding question were excluded.

The search-terms breast neoplasms, postoperative period, mastectomy, and lymphedema were used in different combinations to increase the number of possible references.

The search was conducted from July to September 2012. First, the titles and abstracts of the articles were examined to establish whether they corresponded to the guiding question. Subsequently, the full texts of the pre-selected articles were analyzed to establish whether they met the inclusion criteria.

The selected studies were categorized, their relevant data were extracted, and their results were subjected to critical analysis.

After application of the study strategies and following the inclusion and exclusion criteria, the final sample consisted of 10 articles; four of these articles were located in the LILACS database, five were located in PubMed, and one was located in the CINAHL database in Table 1.

\subsection{Categorization of the Studies}

An adapted data collection instrument was used to collect and summarize the data of the selected studies, which included information on their identification, introduction and aims, methodology, description of results, conclusion, and evidence level [13].

The instrument was subjected to a pretest to establish its fit with the aims of the study and to ensure its rigor. Two articles meeting the inclusion criteria were used to identify the most appropriate manner to use the instrument and to verify the validity of its content.

\subsection{Analysis of the Included Studies}

Following categorization, the relevant aspects concerning the identification data from the studies and their content relative to the introduction, methods, results, and conclusions were analyzed.

The synthesis of the information was presented in a descriptive manner, and tables were used to summarize the data extracted from the articles, as well as the main findings of the present study. 
Table 1. References resulting from the combination of search terms using the LILACS, PubMed, and CINAHL databases.

\begin{tabular}{|c|c|c|c|}
\hline Combinations & Results & References after Abstract Analysis & References after Full-Text Analysis \\
\hline \multicolumn{4}{|l|}{ LILACS } \\
\hline Breast Neoplasm Lymphedema Mastectomy & 17 & 6 & 3 \\
\hline Breast Neoplasm Lymphedema & 35 & 7 & 1 \\
\hline $\begin{array}{l}\text { Breast Neoplasm Lymphedema Postoperative period } \\
\text { PUBMED }\end{array}$ & 0 & - & - \\
\hline \multicolumn{4}{|l|}{ CINAHL } \\
\hline Breast Neoplasm Lymphedema Mastectomy & 163 & 33 & 1 \\
\hline Breast neoplasm Lymphedema Postoperative Period & 211 & 17 & 0 \\
\hline Total Sample & & & 10 \\
\hline
\end{tabular}

\subsection{Interpretation of Results}

The identified data were discussed and compared to the theoretical knowledge, addressing the implications resulting from the present study.

\subsection{Presentation of the Integrative Review}

The review presents relevant and detailed information on procedures and findings, thus contributing to their critical analysis and to a more thorough understanding of the investigated subject.

\section{Results}

Ten articles were selected for full-text analysis, whereby their data were extracted and analyzed for categorization based on the data collection instrument that was used in the present review. Each article and its corresponding data collection instrument were given an identification number, and thus, an organized information structure was generated. Table 2 lists details of the studies included in this review.

Of the 10 articles composing the sample, four (40\%) were published in Portuguese. The countries of origin of the articles exhibited some variation, as four (40\%) were conducted in Brazil; two (20\%) were conducted in Canada; and India, the United States, and Denmark each had one $(10 \%)$ publication.

Four $(40 \%)$ studies were found in the LILACS database, five (50\%) were found in PubMed, and one (10\%) was found in CINAHL. Regarding the journals, one (10\%) article was published in Revista Latino-Americana de Enfermagem, one (10\%) was published in Escola Enfermagem Anna Nery, one (10\%) was published in Revista Brasileira Ginecologia e Obstetrícia, one (10\%) was published in Acta Paulista de Enfermagem, one (10\%) was published in the Indian Journal of Cancer, one (10\%) was published in The Breast, one (10\%) was published in the Journal of Clinical Oncology, and one (10\%) was
Table 2. Details of the studies included in the review.

\begin{tabular}{|c|c|c|}
\hline Study & Experimental Design & Year/Country \\
\hline Meirelles, et al. [20] & Case-Control & 2006 Brazil \\
\hline Panobianco, et al. [2] & Case-Control & 2009 Brazil \\
\hline Junior, et al. [5] & Case-Control & 2001 Brazil \\
\hline Panobianco, Mamede [18] & Case-Control & 2002 Brazil \\
\hline Nesvold, et al. [21] & Case-Control & 2008 Norway \\
\hline Deo, et al. [19] & Case-Control & 2004 India \\
\hline Gartner, et al. [17] & Cohort & 2010 Denmark \\
\hline Soran, et al. [9] & Cohort & $\begin{array}{l}2006 \text { United } \\
\text { States }\end{array}$ \\
\hline Kwan, et al. [14] & $\begin{array}{c}\text { Randomized controlled } \\
\text { clinical trial }\end{array}$ & 2002 Canada \\
\hline Howell, Watson [15] & $\begin{array}{c}\text { Non-Controlled } \\
\text { Randomized Clinical Trial }\end{array}$ & 2005 Canada \\
\hline
\end{tabular}

published in the International Journal of Palliative Nursing.

Regarding the methodological design of the studies, one $(10 \%)$ was a randomized controlled clinical trial [14]; one $(10 \%)$ was a non-controlled randomized clinical trial [15]; two (20\%) were cohort studies [16,17], and six (60\%) were case-control studies [2,5,18-21].

Regarding the strength of the evidence, eight studies $(80 \%)$ were at evidence level IV, one (10\%) was at level III, and one (10\%) was at level II as showed in Table 3.

The total sample of the ten studies included 4,315 participants. Interviews, physical examinations, and questionnaires were the primary data collection techniques. The average length of the $10(100 \%)$ studies was 11.5 months.

One study classified the grade of lymphedema as stages II and III [20], one (10\%) study described it as grades I and II [15], and eight (80\%) studies classified lymphedema as mild, moderate, or severe $[2,5,14,16-$ $19,21]$. 
Table 3. Characterization of the studies according to classification of lymphedema.

\begin{tabular}{|c|c|c|c|c|c|}
\hline Study & Study Population & $\begin{array}{l}\text { Proportion of } \\
\text { Lymphedema }\end{array}$ & $\begin{array}{c}\text { Degree of } \\
\text { Lymphedema }\end{array}$ & Type of Treatment & Time since Surgery \\
\hline Meirelles, et al. [20] & 36 & 36 (100\%) & $\begin{array}{c}30 \text { (83.3\%) Moderate } \\
6(16.7 \%) \text { Severe }\end{array}$ & $\begin{array}{c}7(19.4 \%) \text { RM } \\
18(50 \%) \text { MRM } \\
11(30.6 \%) \text { BCT } \\
30(83.3 \%) \text { Radiotherapy }\end{array}$ & $\begin{array}{l}6 \text { Months } \\
\text { Minimum }\end{array}$ \\
\hline Panobianco, et al. [2] & 65 & 47 (72.3\%) & $\begin{array}{c}32(49.2 \%) \text { Mild } \\
7 \text { (10.8\%) Moderate } \\
8 \text { (12.3\%) Severe }\end{array}$ & $\begin{array}{c}35(53.8 \%) \text { BCT } \\
21(32.3 \%) \text { MRM } \\
9(13.8 \%) \text { RM } \\
48 \text { (73.8\%) Radiotherapy }\end{array}$ & 5 to 10 Years \\
\hline Junior, et al. [5] & 109 & $15(14 \%)$ & $\begin{array}{c}10(67 \%) \text { Mild } \\
4(27 \%) \text { Moderate } \\
1(6 \%) \text { Severe }\end{array}$ & $\begin{array}{c}86(78.8 \%) \\
\text { MRM Patey } \\
23(21.2 \%) \\
\text { MRM Madden }\end{array}$ & Follow up Visit \\
\hline $\begin{array}{l}\text { Panobianco, } \\
\text { Mamede [18] }\end{array}$ & 17 & $11(64.7 \%)$ & $\begin{array}{c}9(81.8 \%) \text { Mild } \\
2 \text { (18.2\%) Moderate }\end{array}$ & $\begin{array}{c}10(58.8 \%) \text { MRM } \\
7(41.2 \%) \text { BCT } \\
14(82.3 \%) \text { Radiotherapy } \\
14(82.3 \%) \\
\text { Chemotherapy }\end{array}$ & 3 Months \\
\hline Nesvold, et al. [21] & 263 & 43 (16.4\%) & $\begin{array}{c}34 \text { (79.1) Mild } \\
9 \text { (20.9\%) Severe }\end{array}$ & $\begin{array}{c}186(70.7 \%) \text { BCT } \\
77 \text { (29.3\%) RM } \\
93 \text { (63\%) Radiotherapy } \\
266 \text { (89\%) MRM }\end{array}$ & 2 to 6 Years \\
\hline Deo, et al. [19] & 299 & $100(33.5 \%)$ & $\begin{array}{c}83(82.8 \%) \text { Mild } \\
17 \quad(17.2 \%) \text { Severe }\end{array}$ & $\begin{array}{c}12(4 \%) \text { RM } \\
202(67 \%) \text { Radiotherapy } \\
243(81 \%) \text { Chemotherapy } \\
234 \text { (78\%) Hormone Therapy }\end{array}$ & $\begin{array}{l}2 \text { Years } \\
\text { Minimum }\end{array}$ \\
\hline Gartner, et al. [17] & 3,253 & $1,212(37 \%)$ & $\begin{array}{c}604(49 \%) \text { Mild } \\
463 \text { (38\%) Moderate } \\
145(12 \%) \text { Severe }\end{array}$ & $\begin{array}{c}1105 \text { (33.9\%) MRM } \\
706 \text { (21.6\%) BCT } \\
734 \text { (22.5\%) Radiotherapy }\end{array}$ & $\begin{array}{l}3 \text { Years } \\
\text { Minimum }\end{array}$ \\
\hline Soran, et al. [9] & 156 & $52(33 \%)$ & $\begin{array}{c}43(82.7 \%) \text { Mild } \\
9(17.3 \%) \text { Moderate }\end{array}$ & $\begin{array}{c}123 \text { (78.8\%) Radiotherapy } \\
50 \text { (32\%) MRM }\end{array}$ & Follow up Visit \\
\hline Kwan, et al. [14] & 112 & $14(12.5 \%)$ & 30\% - 70\% Mild & 46 (41\%) BCT and Radiotherapy & 2 to 7 Years \\
\hline Howell, Watson [15] & 4 & $4(100 \%)$ & $\begin{array}{c}2(50 \%) \text { Mild } \\
2 \text { (50\%) Moderate }\end{array}$ & $\begin{array}{c}2 \text { (50\%) Mastectomy } \\
3 \text { (75\%) Chemotherapy } 4 \text { (100\%) } \\
\text { Radiotherapy }\end{array}$ & 1 to 4 Years \\
\hline
\end{tabular}

BCT: Breast Conservation Therapy, MRM: Modified Radical Mastectomy, RM: Radical Mastectomy.

\section{Discussion}

Of the 10 assessed articles, four were found in the LILACS database, five were found in PubMed, and one was found in the CINAHL database. Of these three databases, PubMed provided the most information on the investigated subject.

Some of the journals in which the articles were published were medical. Other journals were related to the physical therapy field, whereas three were nursing journals: the International Journal of Palliative Nursing, Revista da Escola de Enfermagem Anna Nery, and Revista Latino-Americana de Enfermagem.

Most of the articles were published during the last decade, demonstrating that the investigated subject undergoes continual updating and elicits the interest of healthcare professionals. Variations were found in geographical origin of the studies on the prevalence of lymphedema, and a significant number of articles were from Brazil. The expected frequency of lymphedema among the Brazilian population is high because of the need to apply more radical cancer treatments due to late diagnosis (when the tumors are in more advanced stages of pro- gression), thus resulting in a significant increase in the morbidities associated with breast cancer [22].

Analysis of the methodological characteristics of the studies revealed that all of them applied quantitative approaches and that the case-control design was the most frequently used.

Of the ten articles included in the present review, eight presented level IV evidence, one presented level III evidence, and one presented level II evidence.

The most prevalent data collection techniques were interviews and physical examinations, which were performed in nine (90\%) studies. Questionnaires were used in five (50\%) studies, clinical record reviews were used in two (20\%) studies, and research forms were used in one (10\%) study.

The research tools used in quantitative studies include questionnaires, directed observations, randomized data from clinical records, and physical and mental diagnoses; furthermore, the samples are larger compared with qualitative research [23]. The sample was larger than 100 participants in six (60\%) of the articles that were analyzed in the present review. 
The women who were treated for cancer varied in age from 18 to 80 years, with a higher prevalence of participants who were older than 40 years.

Advanced age correlates with the appearance of lymphedema because fibrosis of the lymphatic vessels starts by the fourth decade of life [4]. The total number (n) of participants of all the studies combined was 4315, and lymphedema appeared in 1527 (35.3\%) of the women.

Regarding the measurement criteria adopted by the studies, objective methods were predominantly used in nine (90\%) studies, whereas subjective methods were predominantly used in only two (20\%) studies. Among the objective methods, eight (80\%) studies used the arm circumference as the measurement criterion, and three studies (30\%) used the volume of displaced water.

Lack of standardization was found in the methods for measuring the arm circumference. In some studies, the cutoff point to define lymphedema varied from a difference of 1 to $6 \mathrm{~cm}$ between the two upper limbs, whereas in one study, lymphedema was defined as a circumference of 10 to $15 \mathrm{~cm}$ in the arm ipsilateral to the mastectomy.

Regarding the time elapsed since surgery, the prevalence of lymphedema during the late postoperative period was evident in all the assessed studies; in four (40\%) studies, lymphedema was identified zero to 12 months after surgery, and in six (60\%) studies, it occurred 12 months or more after surgery.

Regarding the severity of lymphedema in all ten studies combined, 824 (53.9\%) patients exhibited mild lymphedema, 517 (33.8\%) exhibited moderate lymphedema, and 186 (12.3\%) exhibited severe lymphedema. Therefore, the mild degree of lymphedema was the most prevalent among the participants who developed this condition during the postoperative period.

Although lymphedema lasts for life, some of its associated problems might be avoided, and the quality of nursing care greatly affects the outcomes [24].

Effective communication between nurses and patients is necessary to ensure that the former will have sufficient time to assess the needs of the latter. Cultural, personal, and spiritual factors must be assessed to improve the quality of patient care [25-27].

Regarding surgery in all ten studies combined, 1,686 (37.7\%) participants were subjected to mastectomy, of whom 1,581 (35.4\%) underwent modified radical mastectomy and 105 (2.3\%) underwent radical mastectomy. Breast-conserving surgery, such as lumpectomy and quadrantectomy, was performed in 991 (22.1\%) women.

Regarding complementary treatments, 234 (5.2\%) women were subjected to hormone therapy, 260 (5.8\%) underwent chemotherapy, and 1,294 (28.9\%) underwent radiotherapy.

Thus, the results demonstrate that many women are subjected to mastectomy because surgery is still a firstline treatment. In addition, an increasing number of patients are diagnosed late (with their tumors at more advanced stages), thus requiring more radical surgical procedures. Modified radical mastectomy was the most frequently performed surgical technique.

Certain risk factors, including the number of dissected lymph nodes, are associated with an increased incidence of lymphedema following breast cancer treatment [28].

Another significant finding was the number of participants subjected to complementary radiotherapy. In six of the analyzed articles, more than a half of the participants underwent radiotherapy.

Radiotherapy is an important risk factor for lymphedema. Postoperative radiotherapy induces vasoconstriction of the lymph vessels due to fibrosis, causing marked impairment of lymph node function and changes in the immune response [4].

Based on the findings of the present review, we recommend employing resources to explain the importance of patient self-care during the postoperative period. The use of conservative therapies should be recommended to reduce the occurrence of complications. The combination of axillaries lymph node dissection and radiotherapy, especially on the axillaries area, must be avoided because this dual treatment damages the regional lymph node chain [29].

Professional nurses who are qualified to apply effective strategies of prevention and health education might contribute to the treatment of upper arm lymphedema, thereby hindering its progression to more severe stages.

\section{Conclusions}

Analysis of the selected studies revealed that lymphedema has its highest prevalence during the late postoperative period and appears from months to several years after breast cancer surgery.

Regarding the degree of severity of lymphedema, the mild forms were the most prevalent, even in the studies in which follow-up was performed for many years after surgery.

These findings demonstrate that many women undergoing treatment for breast cancer adopt strategies for the prevention and control of lymphedema, which indicates their awareness of self-care techniques, knowledge about this morbidity, and requirement for life-long treatment.

Nurses, as professionals who recognize the requirements of care and plan, provide a wide variety of interventions in their daily practice that may ensure the continuity of treatment-particularly by applying strategies of prevention and education that emphasize the importance of controlling lymphedema throughout the patients' lives. 


\section{Relevance to Clinical Practice}

It is worth stressing that preventive care should begin as soon as the patients begin treatment for breast cancer. As revealed in the present study, such strategies could be started during both the immediate and late postoperative periods, aiming at early detection of lymphedema and preventing the increase of its prevalence during the late stages of the postoperative period after mastectomy.

\section{REFERENCES}

[1] Brazil Health Ministry, National Cancer Institute, "2011 Estimates: Incidence of Cancer in Brazil,” Brazil Health Ministry, National Cancer Institute, Rio de Janeiro, 2011.

[2] M. S. Panobianco, M. V. Parra, A. M. Almeida, M. A. S. Prado and P. A. P. Magalhães, "Study of the Adherence to Strategies for Prevention and Control of Lymphedema in Women Subjected to Mastectomy,” Escola Anna Nery Revista de Enfermagem, Vol. 13, No. 2, 2009, pp. 161168.

http://dx.doi.org/10.1590/S1414-81452009000100022

[3] L. C. Silva, "Breast Cancer and Psychological Suffering: Aspects Related to Femininity,” Psicologia em Estudo, Maringá, Vol. 13, No. 2, 2008, pp. 231-237.

[4] L. F. Rezende, A. V. R. Rocha and C. S. Gomes, "Assessment of the Risk Factors for Lymphedema Following Treatment for Breast Cancer," Journal Vascular Brasileiro, Vol. 9, No. 4, 2010, pp. 233-238. http://dx.doi.org/10.1590/S1677-54492010000400005

[5] R. Freitas Júnior, L. F. J. Ribeiro, L. Taia, D. Kajita, M. V. Fernandes and G. S. Queiroz, "Linfedema em Pacientes Submetidas à Mastectomia Radical Modificada,” Rev. Bras. Ginecol. Obstet., Vol. 23, No. 4, 2001, pp. 205-208. http://dx.doi.org/10.1590/S0100-72032001000400002

[6] H. S. M. Cho, G. C. Davis, J. E. Paek, R. Rao, H. Zhao, X. J. Xie, M. G. Yousef, T. Fedric, D. H. Euhus and M. Leitch, "A Randomised Trial of Nursing Interventions Supporting Recovery of the Postmastectomy Patient," Journal of Clinical Nursing, Vol. 22, No. 7-8, 2013, pp. 919-929.

[7] V. Harmer, "Breast Cancer-Related Lymphoedema: Risk Factors and Treatment," British Journal of Nursing, Vol. 18, No. 3, 2009, pp.166-172.

[8] A. Bergmann, "Incidence and Risk Factors for Lymphedema after Surgical Treatment of Breast Cancer: Study of a Hospital-Based Cohort,” Brazil Health Ministry, Oswaldo Cruz Foundation, National School of Public Health, Rio de Janeiro, 2005.

[9] A. Soran, G. Dangelo, M. Begovic, F. Ardic, A. Harlak, S. H. Wieand, V. G. Vogel and R. R. Johnson, "Breast Cancer Related Lymphedema-What Are Significant Predictors and How They Affect the Severity of Lymphedema?” Breast Journal, Vol. 12, No. 6, 2006, pp. 536-543. http://dx.doi.org/10.1111/j.1524-4741.2006.00342.x

[10] K. D. S. Mendes, R. C. C. P. Silveira and C. M. Galvão, "Integrative Review: A Research Method to Incorporate
Evidence in Health and Nursing," Revista Texto \& Contexto de Enfermagem, Florianópolis, Vol. 17, No. 4, 2008, pp. 758-764.

[11] R. Whittemore and K. Knalf, "The Integrative Review: Update Methodology,” Journal of Advanced Nursing, Vol. 52, No. 5, 2005, pp. 546-553.

http://dx.doi.org/10.1111/j.1365-2648.2005.03621.x

[12] D. L. Pompeo, L. A. Rossi and C. M. Galvão, "Integrative Review: Initial Step in the Process of Validation of the Nursing Diagnosis," Acta Paulista de Enfermagem, Vol. 22, No. 4, 2009, pp. 434-438. http://dx.doi.org/10.1590/S0103-21002009000400014

[13] M. T. Souza, M. D. Silva and R. Carvalho, "Integrative Review: What It Is and How to Do It,” Revista Einstein, Vol. 8, No. 1, 2010, pp. 102-106.

[14] W. Kwan, J. Jackson, L. M. Weir, C. Dingee, G. Mcgregor and I. A. Olivotto, "Chronic Arm Morbidity after Curative Breast Cancer Treatment: Prevalence and Impact on Quality of Life,” Journal of Clinical Oncology, Vol. 20, No. 20, 2002, pp. 4242-4248. http://dx.doi.org/10.1200/JCO.2002.09.018

[15] D. Howell and M. Watson, "Evaluation of a Pilot NurseLed, Community Based Treatment Programme for Lymphedema,” International Journal Palliative Nursing, Vol. 11, No. 2, 2005, pp. 62-69.

[16] P. C. Alves, M. C. L. Santos and A. F. C. Fernandes, "Stress and Coping Strategies for Women Diagnosed with Breast Cancer: A Transversal Study,” Online Brazilian Journal of Nursing, Vol. 11, No. 2, 2012, pp. 305-318. http://dx.doi.org/10.5935/1676-4285.20120028

[17] R. Gartner, M. B. Jensen, L. Kronborg, M. Ewertz, H. Kehlet and N. Kroman, "Self-Reported Arm Lymphedema and Functional Impairment after Breast Cancer Treatment-A Nationwide Study of Prevalence and Associated Factors,” The Breast, Vol. 19, No. 6, 2010, pp. 506-515. http://dx.doi.org/10.1016/j.breast.2010.05.015

[18] M. S. Panobianco and M. V. Mamede, "Complications and Intercurrent Events Associated with Edema of the Arm during the First Three Months after Mastectomy,” Revista Latino-Americana de Enfermagem, Vol. 10, No. 4, 2002, pp. 544-551. http://dx.doi.org/10.1590/S0104-11692002000400012

[19] S. V. S. Deo, S. Ray, G. K. Rath, N. K. Shukla, M. Kar, S. Asthana and V. Raina, "Prevalence and Risk Factors for Development of Lymphedema Following Breast Cancer Treatment," Indian Journal of Cancer, Vol. 41, No. 1, 2004, pp. 8-12.

[20] M. C. C. Meirelles, M. V. Mamede, L. Souza and M. S. Panobianco, "Assessment of Physical Therapy Techniques in the Treatment of Lymphedema after Breast Surgery in Women,” Revista Brasileira de Fisioterapia. Vol. 10, No. 4, 2006, pp. 393-399. http://dx.doi.org/10.1590/S1413-35552006000400006

[21] I. G. Nesvold, A. Dahl, E. Lokkevik, A. Mengshoel and S. Fossá, "Arm and Shoulder Morbidity in Breast Cancer Patients after Breast-Conserving Therapy versus Mastectomy," Acta Oncologica, Vol. 47, No. 5, 2008, pp. 835-842. http://dx.doi.org/10.1080/02841860801961257

[22] A. Bergmann, I. E. Mattos and R. J. Koifman, “Diagnosis 
of Lymphedema: Analysis of the Methods Used in the Assessment of the Upper Limb after Axillary Lymph Node Dissection for the Treatment of Breast Cancer," Revista Brasileira de Cancerologia, Vol. 50, No. 4, 2004, pp. 311-320.

[23] E. G. Turato, "Qualitative and Quantitative Methods in the Field of Health: Definitions, Differences, and Research Subjects,” Revista de Saúde Pública, Vol. 39, No. 3, 2005, pp. 507-514.

http://dx.doi.org/10.1590/S0034-89102005000300025

[24] J. Marrs, "Lymphedema and Implications for Oncology Nursing Practice,” Clinical Journal of Oncology Nursing, Vol. 11, No. 1, 2007, pp. 19-21.

http://dx.doi.org/10.1188/07.CJON.19-21

[25] L. H. Tay, E. Ang and D. Hegney, “Nurses' Perceptions of the Barriers in Effective Communication within Patient Cancer Adults in Singapore,” Journal of Clinical Nursing, Vol. 21, No. 17-18, 2012, pp. 2647-2658. http://dx.doi.org/10.1111/j.1365-2702.2011.03977.x

[26] D. C. Hayes, M. Janda, B. Cornish, D. Battistutta and B. Newman, "Lymphedema after Breast Cancer: Incidence,
Risks, Factors \& Effect on Upper Body Function,” Journal of Clinical Oncology, Vol. 26, No. 21, 2008, pp. 3536-3542. http://dx.doi.org/10.1200/JCO.2007.14.4899

[27] R. B. Jones, J. Pearson, A. J. Cawsey, D. Bental, A. Barrett, J. White and W. H. Gilmour, "Effect of Different Forms of Information Produced for Cancer Patients on Their Use of the Information, Social Support, and Anxiety: Randomized Trial,” British Medical Journal London, Vol. 332, No. 7547, 2006, pp. 942-948. http://dx.doi.org/10.1136/bmj.38807.571042.68

[28] T. Schulze, J. Mucke, J. Markwardt, P. M. Schlag and A. Bembenek, "Long-Term Morbidity of Patients with Early Breast Cancer after Sentinel Lymph Node Biopsy Compared to Axillary Lymph Node Dissection,” Journal of Surgical Oncology, Vol. 93, No. 2, 2006, pp.109-119. http://dx.doi.org/10.1002/jso.20406

[29] C. Kim, D. Kang and J. Park, “A Meta-Analysis of Aerobic Exercise Interventions for Women with Breast Cancer,” Western Journal of Nursing Research, Vol. 31, No. 4, 2009, pp. 437-461. http://dx.doi.org/10.1177/0193945908328473 